The University of San Francisco

USF Scholarship: a digital repository @ Gleeson Library | Geschke Center

Could the Work System Method Embrace Systems Concepts

More Fully

Steven Alter

Follow this and additional works at: https://repository.usfca.edu/at

Part of the Business Commons 


\title{
COULD THE WORK SYSTEM METHOD EMBRACE SYSTEMS CONCEPTS MORE FULLY?
}

\author{
Steven Alter \\ University of San Francisco \\ alter@usfca.edu
}

\section{ABSTRACT}

The work system method was developed iteratively with the overarching goal of helping business professionals understand IT-reliant systems in organizations. It uses general systems concepts selectively, and sometimes implicitly. For example, a work system has a boundary, but its inputs are treated implicitly rather than explicitly. This paper asks whether the further development of the work system method might benefit from integrating general systems concepts more completely. After summarizing aspects of the work system method, it dissects some of the underlying ideas and questions how thoroughly even basic systems concepts are applied. It also asks whether and how additional systems concepts might be incorporated beneficially. The inquiry about how to use additional system ideas is of potential interest to people who study systems in general and information systems in particular because it deals with bridging the gap between highly abstract concepts and practical applications.

Keywords: General Systems Theory, Work Systems, Work System Method, Systems Analysis Methods, Design Methodologies, Socio-Technical Design, User Involvement 


\section{BACKGROUND}

The idea of using the concept of work system as the core of a systems analysis method for business professionals was first published in Alter (2002), although the ideas had percolated for over a decade. Experience as vice president of a manufacturing software company in the 1980 s convinced me that many business professionals need a simple, yet organized approach for thinking about systems without getting swamped in details. Such an approach would have helped our customers gain greater benefits from our software and consulting, and would have helped us serve them more effectively across our entire relationship. A return to academia and production of an IS textbook provided an impetus to develop a set of ideas that might help. Starting in the mid-1990s I required employed MBA and EMBA students to use the ideas in an introductory IS course to do a preliminary analysis of an information system in their own organizations. The main goal was to consolidate their learning; a secondary benefit was insight into whether the course content could actually help people understand systems in business organizations.

To date over 300 group and individual papers have contributed to the development of the work system method (WSM). At each stage, the papers attempted to use the then current version of WSM. With each succeeding semester and each succeeding cycle of papers, I tried to identify which confusions and omissions were the students' fault and which were mine because I had not expressed the ideas completely or clearly enough. 
Around 1997 I suddenly realized that I, the professor and textbook author, had been confused about what system the students should be analyzing. Unless they are focusing on software or hardware details, business professionals thinking about information systems should not start by describing or analyzing the information system or the technology it uses. Instead, they should start by identifying the work system and summarizing its performance gaps, opportunities, and goals for improvement. Their analysis should focus on improving work system performance, not on fixing information systems. The necessary changes in the information system would emerge from the analysis, as would other work system changes separate from the information system but necessary before information system improvements could have the desired impact.

After additional publications (available at http://www.stevenalter.com/newsletter.htm) helped develop various aspects of WSM, the overall approach became mature enough to warrant publication of a book (Alter, 2006) that combines and extends the main ideas from the various papers, creating a coherent approach that is organized, flexible, and based on well-defined concepts. Use to date by MBA and EMBA students (early career business professionals) indicates that WSM might be quite useful in practice. Further development of WSM might proceed in many directions, including improving the concepts, testing specific versions in real world settings, and developing online tools that make WSM easier to use and more valuable.

WSM uses system concepts, but the priority in developing WSM always focused on practicality. System concepts and system-related methods that seemed awkward or 
difficult to apply were not included in WSM. For example, WSM might have incorporated certain aspects of soft system methodology (SSM) developed over several decades by the British researcher Peter Checkland (1999). An area of similarity is SSM's identification of 6 key aspects of a "human activity system." Those include customers, actors, transformations, worldview, owner, and environment. Based on an unproven belief that SSM is too abtract and too philosophical to be used effectively by most (American) MBA and EMBA students, WSM was designed to be very flexible but also much more prescriptive than SSM and much more direct about suggesting topics and issues that are often relevant for understanding IT-reliant work systems.

At this point in the development of WSM it is worthwhile to ask whether additional systems concepts might be incorporated beneficially and might contribute to its value for practitioners. Searching for possibilities is a bit awkward because there is very little agreement about what constitutes general systems theory and general systems thinking.

"General Systems Theory (GST) integrates a broad range of special system theories by naming and identifying patterns and processes common to all of them. By use of an overarching terminology, it tries to explain their origin, stability and evolution. While special systems theory explains the particular system, GST explains the systemness itself, regardless of class or level.” (Skyttner, 1996)

Published as Alter, S., "Could the Work System Method Embrace Systems Concepts More 4 Fully?" Information Resource Management Journal, 20(2), April-June 2007, pp. 33-43. 
A system is not something presented to the observer, it is something to be recognized by him. Most often the word does not refer to existing things in the real world but rather to a way of organizing our thoughts about the real world." ... 'A system is anything unitary enough to deserve a name.' (Weiss, 1971) ... 'A system is anything that is not chaos' (Boulding, 1964) ...[A] system is 'a structure that has organized components.' (Churchman, 1979).” (Skyttner, 2001)

One of the problems in trying to incorporate general system ideas is that so many different types of systems fit under the GST umbrella (Larses and El-khoury, 2005):

- Concrete (living, non-living), conceptual, or abstract

- Open, closed, or isolated

- Decomposable, near-decomposable, or non-decomposable

- Static or dynamic

- $\quad$ Black, gray, or white box

This paper dissects some of the ideas underlying WSM and questions how faithfully even basic systems concepts are incorporated into it. This paper proceeds as follows. After summarizing WSM, it summarizes four work systems to illustrate the range of systems that WSM addresses (and conversely, the types of systems it does not address). Building on this clarification of the context, the paper looks at typical concepts from writings about the systems approach or general systems. In each case it discusses whether those ideas already appear in WSM and whether they might be incorporated to a greater extent. The goal is two-fold, to find directions for improving WSM and to reflect on whether 
typical general systems ideas are truly useful for understanding information systems and other work systems from a business professional's viewpoint.

\section{THE WORK SYSTEM METHOD}

WSM focuses on work systems rather than the information systems that support them and often overlap with them. WSM is designed to produce shared understandings that can lead to better technical specifications needed to develop software. It does not produce the type of specification that might be converted mechanically into software. Although WSM can be used for totally new systems, its basic form assumes that a set of problems or opportunities motivate the analysis of an existing work system. The structure and content of WSM attempt to provide both conceptual and procedural knowledge in a readily usable form, and try to express that knowledge in everyday business language.

Definition of work system. A work system is a system in which human participants and/or machines perform work using information, technology, and other resources to produce products and/or services for internal or external customers. Typical business organizations contain work systems that procure materials from suppliers, produce products, deliver products to customers, find customers, create financial reports, hire employees, coordinate work across departments, and perform many other functions. Almost all significant work systems in business and governmental organizations employing more than a few people cannot operate efficiently or effectively without using IT. Most practical IS research is about the development, operation, and maintenance of Published as Alter, S., "Could the Work System Method Embrace Systems Concepts More 6 Fully?” Information Resource Management Journal, 20(2), April-June 2007, pp. 33-43. 
such systems and their components. In effect, the IS field is basically about IT-reliant work systems. (Alter, 2003)

Work system framework. The nine elements of the work system framework (Alter, 2003, 2006) are the basis for describing and analyzing an IT-reliant work system in an organization. Even a rudimentary understanding of a work system requires awareness of each of the nine elements. Four of these elements (work practices, participants, information, and technologies) constitute the work system. The other five elements that fill out a basic understanding of the work system include the products and services produced, customers, environment, infrastructure, and strategies.

Work system life cycle model. WSM's other basic framework describes how work systems change over time. Unlike the system development life cycle (SDLC), which is basically a project model rather than a system life cycle, the WSLC is an iterative model based on the assumption that a work system evolves through a combination of planned and unplanned changes. Consistent with Markus and Mao's (2004) emphasis on the distinction between system development and system implementation, the planned changes occur through formal projects with initiation, development, and implementation phases. The unplanned changes are ongoing adaptations and experimentation that adjust details of the work system without performing formal projects. In contrast to controloriented versions of the SDLC, the WSLC treats unplanned changes as part of a work system's natural evolution. Ideas in WSM can be used by any business or IT professional at any point in the WSLC. The steps in WSM (summarized later) are most pertinent in 
the initiation phase as individuals think about the situation and as the project team negotiates the project's scope and goals.

Information systems as a special case of work systems. Work system is a general case of systems operating within or across organizations. Special cases of work systems include information systems, projects, supply chains, e-commerce web sites, and totally automated work systems. For example, an information system is a work system whose work practices are devoted to processing information, i.e., capturing, transmitting, storing, retrieving, manipulating, and displaying information. Similarly, a project is a work system designed to produce a product and then go out of existence. The relationship between the general case and the special cases is useful because it implies that the special cases should inherit vocabulary and other properties of work systems in general. (Alter, 2005) Based on this hierarchy of cases, an analysis method that applies to work systems in general should also apply to information systems and projects.

\section{Examples of Information Systems}

A common problem in reading general discussions of information systems is the lack of clarity about which types of information systems are being discussed and which are being ignored. Similarly, discussions of general systems theory are often unclear about the types of systems for which specific concepts or principles are relevant. WSM is designed for situations in which an information system is viewed as an IT-reliant work system devoted to processing information. WSM is less applicable if the information system is 
viewed as a technical artifact that operates on a computer and is used by "users" who are external to the system. The following four examples from Alter (2006) illustrate the types of information systems to which WSM applies.

Work system \#1: How a bank approves commercial loans. A large bank's executives believe that its current methods for approving commercial loans have resulted in a substandard loan portfolio. They are under pressure to increase the bank's productivity and profitability. The work system for approving loan applications from new clients starts when a loan officer helps identify a prospect's financing needs. The loan officer helps the client compile a loan application including financial history and projections. A credit analyst prepares a "loan write-up" summarizing the applicant's financial history, projecting sources of funds for loan payments, and discussing market conditions and the applicant's reputation. Each loan is ranked for riskiness based on history and projections. Senior credit officers approve or deny loans of less than $\$ 400,000$; a loan committee or executive loan committee approves larger loans. The loan officer informs the loan applicant of the decision.

Work system \#2: How a software vendor tries to find and qualify sales prospects. A software vendor sells HR software to small and medium sized enterprises. It receives initial expressions of interest through inquiries from magazine ads, web advertising, and other sources. A specialized sales group contacts leads from other sources and asks questions to qualify them as potential clients. A separate outside sales force contacts qualified prospects, discusses software capabilities, and negotiates a purchase or usage 
deal. Management is concerned that the sales process is inefficient, that it misses many good leads, and that the outside sales group receives too many unqualified prospects.

Work system \#3: How consumers buy gifts using an ecommerce web site. The web site of a manufacturer of informal clothing for teenagers has not produced the anticipated level of sales. Surveys and logs of web site usage reveal that customers who know exactly what they want quickly find the product on the web site and make the purchase. Customers who are not sure what they want, such as parents buying gifts for teenagers, often find it awkward to use the site, often leave without making a purchase, and have a high rate of after purchase returns. The company wants to extend existing sales channels. Its managers want to improve the level of sales by improving the customer experience.

Work system \#4: How an IT group develops software. The IT group buys commercial application software whenever possible, but also produces home-grown software when necessary. Many of the IT group's software projects miss schedule deadlines, go over budget, and/or fail to produce what their internal customers want. Software developers often complain that users can't say exactly what they want and often change their minds after programming has begun. Users complain that the programmers are arrogant and unresponsive. Use of the company's computer aided software engineering (CASE) software is uneven. Enthusiasts think it is helpful, but other programmers think it interferes with creativity. The IT group's managers believe that failure to attain greater success within several years could result in outsourcing much of the group's work. 
Several features of the four examples should be noted. First, each example concerns an IT-reliant work system, and each of these work systems is an information system. (Yes, software development, work system \#4, is basically an information system). In addition, as the analysis proceeds in each case, the system to be analyzed will be defined based on the problem or opportunity posed by management. The system will not be defined based on the software that happens to be used as a part of the system.

\section{Three Levels for Using the Work System Method}

The current version of WSM (Alter, 2006) consists of three problem-solving steps (SP, AP, and RJ) related to systems in organizations.

- SP - Identify the System and Problems: Identify the work system that has the problems that launched the analysis. The system's size and scope depend on the purpose of the analysis.

- AP - Analyze the system and identify Possibilities: Understand current issues and find possibilities for improving the work system.

- RJ - Recommend and Justify changes: Specify proposed changes and sanity-check the recommendation.

Recognizing the varied nature of analysis situations and goals, WSM can be used at three levels of detail and depth. The level to use depends on the user's particular situation 
- Level One (Define): Be sure to remember the three main steps when thinking about a system in an organization.

- Level Two (Probe): Within each main step, ask questions that are typically important. These questions include:

- Five SP questions (What is the system? What is the problem? What are the constraints? And so on)

○ Ten AP questions (One question about how well each work system is operating, and one question about the work system as a whole)

- Ten RJ questions (What is the recommendation? How does it compare to an ideal system? Was the original problem solved? What new problems will the recommendation cause? How favorable is the balance of costs and benefits? And so on)

- Level Three (Drill Down): For each question within each step, apply guidelines, concepts, and checklists that are often useful.

The most recent version of WSM uses an electronic questionnaire, the first page of which is basically a Level One outline of the executive summary of a typical business analysis and recommendation. The next pages present the 25 questions in Level Two, with space to fill in answers. Vocabulary and concepts identified throughout Alter (2006) and arrayed in checklists, templates, and tabular forms provide additional (Level Three) support for the analysis. These tools help in identifying common topics that might be 
considered, providing hints about common issues, and providing blank tables that might be used to summarize specific topics or perspectives.

WSM is built on the assumption that an organized structure combining flexibility with considerable depth can be effective in helping business professionals pursue whatever amount of detail and depth is appropriate. Because WSM is designed to support a business professional's analysis, even Level Three does not approach the amount of detail or technical content that must be analyzed and documented to produce computerized information systems.

\section{WORK SYSTEM METHOD AS A SYSTEMS APPROACH}

At a superficial level WSM surely represents a systems approach because it describes a situation as a system consisting of interacting components that operate together to accomplish a purpose. A closer look is worthwhile, however, because some aspects of WSM use systems concepts in an idiosyncratic manner. In particular, a careful look at the four examples (beyond the scope of this article) would show that each is a system but that describing each as a set of interacting components operating together to accomplish a purpose might miss some insights related to the type of system WSM studies. To reflect on how WSM applies a systems approach, it is possible to look at the form and prominence of basic system concepts within the current version of WSM.

Published as Alter, S., "Could the Work System Method Embrace Systems Concepts More 13 Fully?" Information Resource Management Journal, 20(2), April-June 2007, pp. 33-43. 
Identification of the system. WSM users start their analysis by defining the work system. As a general guideline, the system is the smallest work system that has the problem or opportunity that launched the analysis. The system's scope is revealed by identifying the work practices (typically a business process, but possibly other activities as well) and participants who perform the work.

The observer. Systems thinking recognizes that system is a mental construct imposed on a situation in order to understand it. Different observers have different system views of the same situation. Part of WSM's value is as a way to help people come to agreement about what system they are trying to improve.

Boundary and environment. The identification of the work system in the initial part of WSM automatically sets the boundaries. The work system framework includes some elements that are part of the work system and some that are outside of the work system. The four elements inside the work system are work practices, people, information, and technologies. The other five elements are not part of the work system but are included in the framework because it tries to identify the components of even a rudimentary understanding of a work system.

Mora et al (2002) noted several logical problems with treatment of the system concept context in an earlier version of the work system framework that was used in 2001. (Context appeared where environment now appears.) They also noted that the customers are not included in the box called context (now environment). These observations are 
accurate from a definitional viewpoint, but the priority in creating WSM is to combine system-related ideas in a way that makes WSM as useful as possible for typical business professionals. Explicitly saying that a work system exists to produce products and services for customers encourages the WSM user to pay special attention to the products and services and customers. Various aspects of the environment such as culture and political issues may matter greatly in some situations and may be unimportant in other situations, but products and services and customers are always important for understanding work systems (including information systems) in organizations.

The term infrastructure is also problematic in relation to boundaries. Real world work systems could not operate without infrastructure owned and managed by the surrounding organization and external organizations. Infrastructure is included as one of the elements for understanding a work system because ignoring external infrastructure may be disastrous. However, it is awkward to treat computer networks, programming languages, IT personnel, and other shared resources as internal parts of the work systems they serve. If these components of infrastructure were treated as internal components of the work system, even small work systems involving a few people and several activities would become gigantic. They would be like an iceberg, with visible aspects of the work system above the water and an enormous mass of shared infrastructure largely invisible below the waterline. To discourage unnecessary attention to distinctions between technology and infrastructure early in the analysis, WSM users creating a "work system snapshot" for summarizing a work system should assume that the difference between technology and 
technical infrastructure is unimportant for the initial summary. The distinction should be explored only if it is important for understanding the work system in greater depth.

Inputs and outputs. The work system framework contains neither the term inputs nor the term outputs. The term output is not used because it sounds too mechanistic and is associated too much with computer programs. In terms of logic and structure, there is no problem in calling a work system's outputs products and services. Also, that terminology helps focus attention on the work system's goal of providing products and services customers want, rather than just producing whatever outputs it is programmed to produce. Even the terms products and services are occasionally problematic. For example, consider a work system that produces entertainment. The product might be described as a temporally sequenced information flow that is sensed and interpreted by viewers (the customers). It also might be viewed as the customer's stimulation, peace of mind, or enjoyment. At minimum there is question about whether the customer plays an active role as a participant in the work system. As the nature of the product becomes more ambiguous, the boundary of the system also becomes more ambiguous.

The work system framework ignores inputs altogether because it assumes that important inputs will be understood implicitly. The first step in the work practices typically will describe something about receiving, transforming, or responding to something that comes from outside of the work system. (If important inputs are not mentioned anywhere in the work practices, it is likely that the summary of work practices will be insufficient.) Also, information from external sources is often listed under the information used or produced 
by the work system. And what about other inputs, such as the air the participants breathe, the food they metabolize as they do their work, or the skills they received from a training course last year? It is easy to say in general that systems have inputs, but substantially more difficult to identify which inputs are worth mentioning in an analysis. The work system framework lacks a slot for inputs because it is easier to infer important inputs from the steps listed in the work practices.

Transformations. The term transformation is particularly meaningful in physical systems such as assembling a set of tangible components to produce an automobile. Transformation is less meaningful for various aspects of each of the work system examples mentioned earlier. For example, it doesn't feel natural to say that the loan approval system transforms loan applications into approvals or denials; nor does it feel natural to say that the ecommerce web site transforms customer desires into purchase decisions. Thus, the term transformation is often unsatisfactory for summarizing the activities that occur within the work system. During the development of WSM, alternatives to the term transformation included activities, actions, business process, and work practices. Work practices was selected because it includes business process and other perspectives for thinking about activities, such as communication, decision making, and coordination.

Goals, controls, and feedback. Most observers say that purposive systems contain control mechanisms that help the system stay on track or help the system move toward equilibrium (as with a thermostat). A thermostat-like goal and feedback metaphor is 
appropriate for heating a house, but doesn't fit well for many information systems. For example, the role of feedback control in the use of the ecommerce web site is not apparent. Similarly, the software development system may or may not have formal feedback mechanisms. Those mechanisms will be more apparent in a highly structured software development environment, and much less apparent in an agile development environment that proceeds through a series of incremental changes that receive individual feedback but may or may not lead to a larger goal. WSM treats control as one of the perspectives for thinking about work practices. The basic question is whether controls are built into existing or proposed work practices, and whether a different type or different amount of control effort would likely generate better results.

Wholeness. One of the major premises of the system approach is that systems should be treated as wholes, not just as a set of components. The structure of WSM is designed to recognize systemic issues, but WSM certainly doesn't favor wholeness over analysis of components. The structure of WSM calls for looking at each element separately and drilling down to understand the elements in enough depth to spot problems within each element. Simultaneously, however, the work system framework contains explicit links between elements, showing the main routes through which they interact in the operation of the work system as a whole.

An interesting issue with wholeness is that many components of work systems are not wholly dedicated to those work systems. The work practices are the activities within the work system, but the participants may be involved in many other work systems. Their 
activities within a particular work system may absorb only an hour a day or an hour a week. Similarly, the information and technologies may be used in other work systems. In the real world, the wholeness of the work system is often challenged when work system participants feel torn about their responsibilities in multiple work systems.

Emergent properties. Users of WSM automatically observe emergent properties when they look at how a system operates as a whole. However, the level of detail and broadbrush modeling used in WSM is usually insufficient to reveal the types of counterintuitive system behaviors (Forrester, 1971) that are sometimes revealed and understood by system modelers using techniques such as systems dynamics.

Hierarchy, subsystems and supersystems. Systems in organizations are typically viewed as subsystems of larger systems. Relationships between information systems and the work systems they support have changed over recent decades. Before real time computing, computerized tracking systems and transaction processing systems were often separate from the manual processes they served or reported. As real time computing became commonplace, information systems became an integral part of the work systems they served. Remove the work system and the information system has no meaning. Turn off the information system and the work system grinds to a halt. All four of the work systems mentioned earlier have some aspect of this feature. All were selected as information systems that are somewhat independent of other work systems, yet major failures in any of these systems would have significant impacts on larger systems or organizations that they serve. 
System elements. Even the idea of system elements can be called into question. The nine elements of the work system framework are different types of things. For example, work practices are different from people (participants) and are different from information. Compare that view of work system elements to Ackoff's (1981) definition of a system as a set of two or more elements that satisfies the following three conditions:

- The behavior of each element has an effect on the behavior of the whole.

- The behavior of the elements and their effects on the whole are interdependent.

- However subgroups of the elements are formed, all have an effect on the behavior of the whole but none has an independent effect on it. (cited by Skyttner, 2001)

In Ackoff's view, each element is a separate component that has the capability of behaving. In contrast, the work system framework says that the work practices are the behaviors and the work system participants and in some highly automated cases the technologies have the capability of behaving. In other words, each work system is basically a separate element in Ackoff's terms. The implication for future development of the work system method is that it might be possible to include explicit forms of interaction between work systems. Currently the only form of interaction included in WSM is the potential use of one work system's products and services in the work practices of another work system.

System evolution. General system theory is primarily concerned with how systems operate, and somewhat less concerned with how they evolve over time. Patterns through which work systems evolve through planned and unplanned change are extremely 
important in WSM because the justification of a proposed system change includes preliminary ideas about how the system can be converted from its current configuration to a desired future configuration. As explained in substantial detail in Alter (2006), the work system life cycle model says much more about the evolution of a work system than is implied by most general system discussions. As WSM develops further it will surely absorb more ideas and principles related to system change, but most of these will probably come from the IS literature and the organizational behavior and innovation literatures rather than from the general systems literature. On the other hand, it is possible that some aspect of Beer's (1981) viable systems model might be incorporated in future explanations or explorations of the work system life cycle model.

Chaos, complexity, entropy, self-organization. Concepts such as chaos, complexity, entropy, and self-organization are often part of sophisticated discussions of systems. Although these ideas are sometimes tossed around at a rather non-specific, metaphoric level (the chaos of everyday management, the complexity of our lives, etc.), bringing these concepts into WSM while maintaining their deeper, more precise meanings in sophisticated discussions of systems seems impractical at this point. Attaining insightful analysis when using the existing WSM vocabulary is challenging enough.

The use of the term complexity in WSM illustrates the challenge of moving toward more advanced concepts. Within the current version of WSM, complexity is applied with its every day meaning and is treated as one of many strategy choices for work practices. Simpler work practices deal with fewer variables and are easier to understand and 
control; the opposite is true for complex work practices. Even with that simple definition, MBA and EMBA students have shown little inclination to use that term when evaluating a work system (i.e., it is too simple or too complex) and little inclination to use it to describe proposed improvements. If they shy away from relatively simple usage of that type, it is unlikely that they would be willing or able to apply advanced understandings of complexity that require insight at a very abstract level.

\section{CONCLUSION}

This reflection on WSM's use of general system concepts is highly subjective because different authors use different definitions of terms and have different views of which terms belong under the umbrella of general systems concepts. Evaluation of WSM in relation to general systems theory is all the more difficult because WSM was not developed as an application of general systems theory. It was developed to provide a set of ideas and tools that business professionals can use when trying to understand and analyze systems from a business viewpoint. At every stage in its development, every choice between maximizing ease of use and maximizing conceptual purity was decided in favor of ease of use.

The review of the relationship between typical system concepts and concepts within WSM showed that WSM uses a system approach and system concepts, but sometimes uses those terms idiosyncratically. Consistent with its practical goal of helping business professionals understand and analyze IT-reliant work systems, WSM adapts system Fully?” Information Resource Management Journal, 20(2), April-June 2007, pp. 33-43. 
concepts within a framework that is easier to understand and apply than any of the frameworks typically associated with general system theory (at least in my opinion).

Real world examples were introduced in this article as a reality check because general systems theory tends to include under one umbrella many different types of systems at vastly different levels (e.g., Miller's (1978) inclusion of cells, organs, organisms, groups, organizations, communities, societies, and supranational systems within the category of living systems). Potential changes in WSM concepts and process should be tested against realistic examples of IT-reliant work systems. If a change would make typical examples clearer to typical business professionals, then it might be appropriate within the spirit of WSM, especially if it could also co-exist with the rest of WSM or if it would make an existing part of WSM unnecessary.

It is unclear whether a detailed review of general system theory and its sophisticated extensions related to concepts such as chaos, complexity, entropy and self-organization might lead to useful improvements in WSM. Although this is a possibility, the path would probably be long. The first step would involve finding real situations in which sophisticated use of these concepts would help in evaluating, analyzing, and designing the types of systems that WSM addresses. It seems likely that sophisticated applications of concepts such as chaos, complexity, entropy, and self-organization are less pertinent to in typical work systems and more pertinent to physical and mathematical systems whose components and component interactions are more amenable to mathematical analysis. 
The original question was "Could the work system method embrace systems concepts more fully?" At this point the answer to that question is a weak maybe. WSM is mature enough that its value to business and IT professionals can be tested in a number of different settings. Informal results thus far show that many users find it useful, and imply that at least some future users will suggest ways to make it easier to use in general or easier to apply to specific types of situations.

If I had to guess, I would say that the suggestions most directly associated with general systems concepts would be related to subset/ superset relationships and supplier/customer (output/input) relationships between separate work systems. The current form of WSM focuses on a single work system and says that it may be convenient to subdivide one work system into several or combine several work systems into one. An effective way to handle relationships between separate work systems without making the analysis too awkward probably would be a very useful extension of the current version of WSM.

At a more theoretical level, it also would be interesting to look at general systems concepts and principles at much greater depth than was possible in this brief paper. For example, Skyttner (2001, pp. 61-64) lists 39 different "widely known laws, principles, theorems, and hypotheses). It would be interesting to look at each in turn and to decide whether it says anything that is both non-obvious about IT-reliant work systems and useful in understanding them in real world situations. 


\section{REFERENCES}

Ackoff, R. (1981) Creating the Corporate Future, New York: John Wiley \& Sons.

Alter, S. (2002) "The Work System Method for Understanding Information Systems and Information System Research,” Communications of the AIS, 9 (6), pp. 90-104.

Alter, S. (2003) “18 Reasons why IT-Reliant Work Systems Should Replace the IT Artifact as the Core Subject Matter of the IS Field," Communications of the AIS, 12 (23), pp. 365-394.

Alter, S. (2005) "Architecture of Sysperanto - A Model-Based Ontology of the IS Field," Communications of the AIS, 15 (1), pp. 1-40.

Alter, S (2006) The Work System Method: Connecting People, Processes, and IT for Business Results, Larkspur CA: Work System Press.

Beer, S. (1981) Brain of the Firm. $2^{\text {nd }}$ ed., Chichester, UK and New York: John Wiley.

Boulding, K. (1964) "General systems as a point of view," in J. Mesarovic, Views on General Systems Theory, New York: John Wiley.

Checkland, P. (1999) Systems Thinking, Systems Practice (Includes a 30-year retrospective), Chichester, UK: John Wiley.

Published as Alter, S., "Could the Work System Method Embrace Systems Concepts More 25 Fully?" Information Resource Management Journal, 20(2), April-June 2007, pp. 33-43. 
Churchman, C. W. (1979) The Design of Inquiring Systems: Basic Concepts of Systems and Organizations, New York, Basic Books.

Forrester, J. (1971, January) “Counterintuitive Behavior of Social Systems,” Technology Review, 73 (3).

Larses, O., and El-Khoury, J. (2005) Review of Skyttner (2001) in O. Larses and J. ElKhoury, "Views on General Systems Theory,” Technical Report TRITA-MMK 2005:10, Royal Institute of Technology, Stockholm, Sweden, Retrieved June 30, 2006 on the World Wide Web:

http://apps.md.kth.se/publication_item/web.phtml?ss brand=MMKResearchPublications \&department_id='Damek'

Markus, M.L. and Mao, J.Y. (2004) "Participation in Development and Implementation Updating an Old, Tired Concept for Today's IS Contexts," Journal of the Association for Information Systems," 5 (11: 14).

Miller, J. G. (1978) Living Systems, New York: McGraw-Hill.

Mora, M., Gelman, O., Cervantes, F., Mejía, M., and Weitzenfeld, A. (2002) “A Systemic Approach for the Formalization of the Information Systems Concept: Why Information Systems are Systems," in J.J. Cano, (Ed.), Critical Reflections on 
Information Systems: A Systemic Approach, Hershey, PA: Idea Group Publishing, pp. 129.

Skyttner, L. (2001) General Systems Theory, Singapore: World Scientific Publishing

Skyttner, L, (1996) "General systems theory: Origin and hallmarks," Kybernetes, London: 25 (6), p. 16, 7 pgs

Weiss, P. (1971) Hierarchically Organized Systems in Theory and Practice, New York: Hafner.

Published as Alter, S., "Could the Work System Method Embrace Systems Concepts More 27 Fully?" Information Resource Management Journal, 20(2), April-June 2007, pp. 33-43. 